\title{
CONCESSION PERIOD DETERMINATION FOR PPP RETIREMENT VILLAGE
}

\author{
Shijing LIU ${ }^{1}$, Hongyu JIN ${ }^{1}$, Benzheng XIE ${ }^{2}$, Chunlu LIU1, ${ }^{*}$, Anthony MILLS ${ }^{1}$ \\ ${ }^{1}$ School of Architecture and Built Environment, Deakin University, Geelong, Australia \\ ${ }^{2}$ School of Management Engineering, Shandong Jianzhu University, Jinan, China
}

Received 19 December 2017; accepted 26 June 2018

\begin{abstract}
Demand for the construction of retirement villages is increasing with the worldwide growth in ageing populations. However, the development of retirement villages can be impeded by many factors, such as limited available land and high investment costs. Public-private partnership (PPP) as an alternative financing mechanism has been widely applied in the construction of public infrastructure projects and may provide new funding sources for building retirement villages. By applying PPP to the construction of retirement villages, the independent living requirements of seniors can be met and the financial difficulty of the construction of retirement villages can be resolved. Similar to other PPP projects, when retirement villages are constructed under a PPP process, the concession period is a key decision variable in relation to the success of the project. The concession period is stated in the project contract between the government and private investors, and stipulates the date when the project ownership and operation are transferred from the private investor back to the government. The government should take detailed information into consideration at the initial project stage when determining the concession period. This paper proposes PPP as a new procurement method to be applied to the construction of rental retirement villages and develops a concession period determination process for PPP retirement village projects with consideration of real options, focusing on the option to defer. An empirical example with alternative scales, which is developed from an existing retirement village in Geelong, Australia, is used to numerically verify the process and the impacts of key variables on the concession period. The determination process provides an alternative tool for governments to design the concession period before the tendering stage and will benefit the development of industries associated with services for the ageing population. This process can also be applied to the construction of other financially non-viable PPP projects such as social housing.
\end{abstract}

Keywords: concession period, option to defer, public-private partnership, real option, retirement village.

\section{Introduction}

There has been steady growth in the ageing population in Australia. Significant increases have been seen in the proportions of older age groups over recent decades. The number of private renters aged 65 and over will increase by 131\% from 2011 to 2031 (Wood, Ong, \& Cigdem, 2017). Expenditure on the Age Pension is by far the largest growing government expense and is projected to be over $\$ 72$ billion in 2023-24 (National Commission of Audit, 2014). As housing costs take more than $30 \%$ of older renters' household gross income, the growth in the ageing population will increase the demand for affordable age-friendly housing and make the provision of sustainable housing for older people of great importance (Aged and Community Service Australia, 2015; Wood, Ong, \& Cigdem, 2014; Xia, Zuo, Skitmore, Chen, \& Rarasati, 2015). Many seniors have to downsize their houses to improve their financial position. The majority of older people prefer to live independently, but this does not necessarily mean they must own a house rather than living in rental accommodation (COTA Australia, 2017). Many countries have their own housing models to support independent living for seniors, such as retirement housing with some support in the UK, independent living communities in the USA and purposebuilt housing for the elderly in Singapore. Retirement villages in Australia are similar to these housing models and have become an emerging accommodation alternative to meet the requirements of retirees, and their development has great potential.

Given the rapidly ageing Australian population, it is important that the government supports the growth of the retirement village sector, which is privately financed,

*Corresponding author. E-mail: chunlu@deakin.edu.au 
houses low-income people, provides safe and secure living environments, and contributes to ageing in place (Aged and Community Service Australia, 2015). Governments and the retirement village industry are having ongoing discussions around proactive and innovative ways to reduce the costs of developing age-friendly affordable housing and to provide incentives for purchasing it (Aged and Community Service Australia, 2015). The rental village model, which currently occupies a limited part of the market, represents the dominant retirement-living model globally and is expected to grow in the Australian retirement-living market (Owen, 2015). The private and notfor-profit sectors play large roles in meeting the needs of seniors and building retirement villages.

Retirement-village development which follows a traditional procurement process requires significant capital investment to construct multiple residential properties (IBISWorld, 2017). Therefore, barriers to entry into the industry are high for small and medium companies, which need more support from the government. It is shown in industry reports that one of the costs associated with retirement villages that reduces feasibility for developers is the Goods and Services Tax (GST). Also, the high costs of land and associated costs make retirement village projects generally less attractive than residential housing projects, and less viable in regional and remote Australia (COTA Australia, 2017; Retirement Village Association, 2011). Low living costs used to be one of the contributing factors to seniors' decisions to relocate to retirement villages (Gardner, Browning, \& Kendig, 2005; Stimson \& Mccrea, 2004). However, as service fees have risen along with higher building costs, economic pressure has become one of the barriers to older people moving into retirement villages (Liu, Ma, \& Liu, 2016).

These realities create a great opportunity to apply public-private partnership (PPP) to the construction of retirement villages as an innovative form of development. PPP, as a collaborative strategic management approach, is widely used across the world to deliver public services, bring together the public and private sectors in a mid-to-long-term relationship, and sustain business prospects that allow the parties to blend their special skills to serve the needs and interests of the public (Alam, Kabir, \& Chaudhri, 2014). This cooperation is one of the most critical success criteria for a PPP project (Osei-Kyei, Chan, Javed, \& Ameyaw, 2017) and is particularly important for developers whose expertise lies in building aged care facilities, as they need to focus on a good relationship with the public sector. The integration of PPP and retirement villages is an option worth considering in relation to meeting the growing market demand for retirement villages and achieving the goal of developing age-friendly affordable housing while reducing government expense and need to build social housing.

When a retirement village is constructed under a PPP process, the concession period is an important variable for the purpose of determining the economic and financial viability of the project, and is often discussed inten- sively during the negotiation period (Shen, $\mathrm{Bao}, \mathrm{Wu}, \& \mathrm{Lu}$, 2007). While the private sector prefers a longer concession period to gain more benefits, this can result in a loss to the government. A shorter concession period may lead to failure to achieve expected returns for the private sector and so a higher level of user charge, which may damage the social benefit (Khanzadi, Nasirzadeh, \& Alipou, 2012; Yu \& Lam, 2013). Therefore, it is important to the success of a PPP retirement village project to determine an appropriate concession period. Many researchers have conducted studies on optimising the length of the concession period, involving diverse methods like net present value (NPV) and real options. Real options theory is a recent improvement to the mathematical model to include additional values for these projects. There may be several types of real options in a PPP project, such as a guarantee option, an option to expand, an option to defer and an option to abandon. Most of the results of these studies are associated with the evaluation of the guarantee option and give a bounded time interval within a range, while their target projects are financially viable ones such as toll roads and highways.

This paper proposes PPP as a new method to construct retirement villages in order to provide an affordable independent living environment for seniors, and defines a specific concession period for PPP retirement village projects associated with early government investment and the option to defer. The process refers to the irreversible investment model developed by Dixit and Pindyck (1994) and the variables are set to fit retirement village projects. The structure of the paper is organised as follows. Following this introduction, the international context of retirement housing models is summarised and then a PPP process is proposed for retirement villages. A literature review of the existing research on concession periods is presented next. Then come the formulas for the proposed model. Real options theory is used to identify the concession period interval and the optimal concession period. An empirical study with alternative scales, which is developed from an existing retirement village, is conducted to verify the model. Lastly, the results are discussed for further implications and a conclusion is drawn.

\section{International experience of retirement housing models}

Different countries vary in their economic conditions and the degree of development of ageing services. These elements determine their views about how best to manage their ageing populations and therefore the formulation of policy in the retirement housing sector. International experience of retirement housing models may provide sources of innovation and learning. These models in two developed countries, the USA and the UK (Jones, Howe, Tilse, Bartlett, \& Stimson, 2010), and two Asian developed countries, Singapore (Yuen \& Soh, 2017) and Japan (Brasor \& Tsubuku, 2014; Tsutsui, 2010), are now investigated in order to examine this international experience. 
Excluding house ownership and private rental, retirement housing can be divided into three categories based on the purpose and level of service provision. The first category is general-purpose housing, which is usually dominated by the public sector, does not provide ageing services and is suitable for older people who can live independently. Examples are senior apartments in the USA, two-room flexi flats in Singapore and rental housing for the elderly in Japan. These homes can be for sale or rental and senior-friendly fittings can be added when needed. Social housing provided by governments for low-income seniors is another option.

Age-specific housing, also called purpose-built housing for the elderly in Singapore, is the second category. This is accommodation that has been specifically constructed for or allocated to older people. Private sectors and local communities play significant roles in the development of this type of housing, which provides daily or continuing care services and support. Subcategories based on architectural and community types include service-integrated housing and housing that provides care services. Some service-integrated housing offers lifestyle and recreation options, such as active adult retirement communities in the USA and retirement communities in Singapore, while others only offer support services within an independent living complex or shared housing. Retirement villages in the UK and USA, sheltered housing in the UK and Singapore, mobile home parks in the USA and silver housing in Japan are examples of independent living complexes, while Abbeyfield housing in the UK and board and care homes in the USA are shared housing. Some housing with care services provide daily support and care, such as assisted living facilities in the USA and the UK and licensed private senior housing in Japan, while other types provide continuing care, in the USA and Japan.

The third category of retirement housing is residential aged care facilities, also called long-term care homes. The most common type and one that is recognised widely is nursing homes, which provide long-term nursing care for seniors who cannot live independently but cannot be cared for at home or in their community. These facilities require high standards of care services and are usually bed-based, operating with government subsidies. Other examples are group homes in Japan and skilled nursing facilities in the USA, which are for older people who have chronic conditions such as dementia.

In Australia, there are similar models in each category, although with different names. To meet the complex needs of different ageing groups the second category, age-specific housing, is attracting more attention, especially the subcategory of the independent living complex. As an intermediate type between general housing and residential care facilities, retirement villages are an effective housing model within the independent living subcategory that can meet most seniors' housing needs, but their development requires more involvement from the government. Compared to development led by only the public or the private sectors individually, a model of partnership between these two parties would bring about improved living environments for older people. The application of PPP to retirement villages could act as a bridge between the public and private sectors.

\section{Practicability of PPP application to retirement villages}

Retirement villages whose construction is dominated by the more efficient private sector would under PPP then fall into the category of quasi-public goods and become an effective component of government-led aged care facilities. There are two important features in the application of PPP to retirement villages. First, PPP is generally applied in the field of infrastructure construction and public services, while retirement villages are also part of the longterm housing infrastructure of public services for seniors, so they complement each other well in this field. Second, investment in retirement villages has the characteristics of being long-term, stable and high security, which is consistent with PPP projects. Applying PPP to retirement villages would not only reduce the government's financial stress, but also utilise the idle funds of the private sector while meeting the living needs of older people (Yang, Zhou, \& Tan, 2017). Under the PPP model, the government transfers the responsibility for retirement village operation to the private sector, but retains vital responsibilities such as policy development and industry supervision. The quality of ageing services is improved through public resource integration and reasonable competition (Tang \& Feng, 2016). The construction of PPP retirement village projects would allow the government and private sector to share the project risks, with positive impacts on both investment and the operation of the projects. The incentive of government subsidies would have a beneficial effect on the net cash flow of such retirement village projects. Alongside the construction of retirement villages, related industries such as ageing services and superannuation could also be developed in common.

The project structure of a PPP retirement village can be similar to those of other PPP projects which have userpay structures. Figure 1 illustrates a potential pattern of PPP application to rental retirement village projects. The government offers public funds as an early investment in a special purpose vehicle (SPV) to reduce the investment cost and strengthen the financial viability of the project. The government assigns an entity representing the public sector to offer part of the total investment and authorises a department to supervise the project. The government also provides land for the construction of the retirement village. The private sector injects the remainder of the needed capital in the total investment and forms an SPV with the government entity. There may be subcontractors assigned by the SPV to take responsibility for constructing and operating the village, and the SPV is allowed to charge senior renters a weekly rent to recover the capital cost during the concession period. In addition to the rental revenue, the SPV can provide other services agreed 


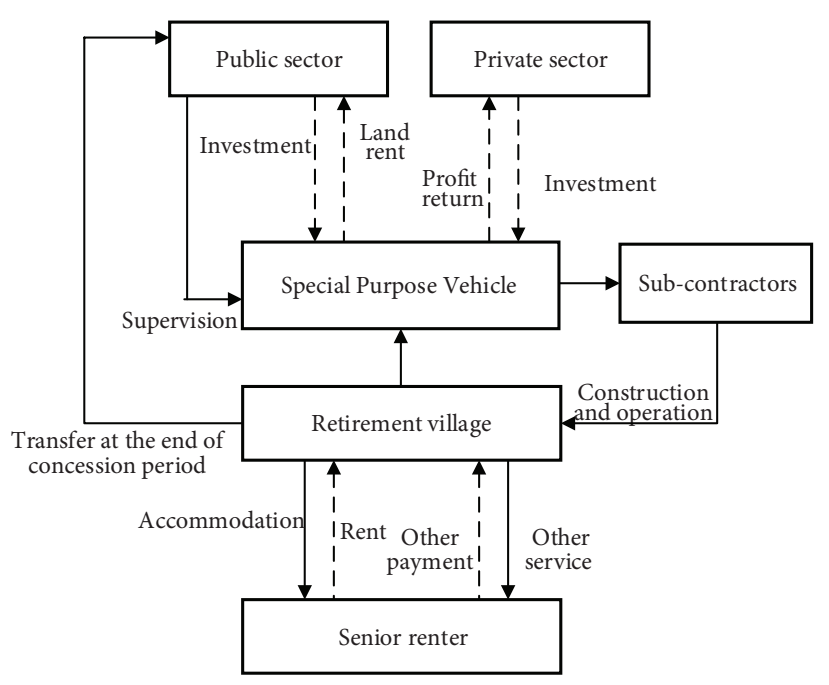

Figure 1. Project structure of a PPP retirement village project

on by the government to gain other operation revenue, such as meal packages, parking and linen services. The private sector receives a profit return from the SPV. The government requires an annual benefit as land rent, as well investment returns from the SPV. When the concession period ends, the retirement village is transferred back to the public sector.

\section{State-of-the-art of concession period determination methods}

The concession period is one of the most important determining variables in a PPP project. Scholars have conducted many studies on the optimisation of the concession period. NPV is used as the analytical foundation for these studies. A summary of the methods based on NPV is given in Table 1. For example, Shen, $\mathrm{Li}$, and $\mathrm{Li}$ (2002) conducted a preliminary study that utilised NPV calculation to create a build-operation transfer concession period model that could protect the interests of both the government and the private sector. Then this model was extend- ed to take risk impacts into consideration (Shen \& Wu, 2005). With the development of simulation techniques, diverse supplementary methods are integrated in order to optimise the concession period. Monte Carlo simulation has been used to simulate the risk factors and uncertainties (Carbonara, Costantino, \& Pellegrino, 2014; Zhang, 2009), while game theory has been added to consider the bargaining behaviours of the parties, both of which refine the concession period to a very narrow range (Bao, Peng, Ablanedo-Rosas, \& Gao, 2015; Shen, Bao, Wu, \& $\mathrm{Lu}, 2007)$. System dynamics is another technique for representing the relationships between the variables in order to optimise the concession period (Khanzadi, Nasirzadeh, \& Alipour, 2012; Song, Song, \& Zhang, 2015). All these simulation techniques improve the accuracy of NPV, but are mostly adapted to transportation projects. Retirement villages as housing projects have some differences from transportation projects.

The traditional NPV method is a static assessment method, as it estimates the value of a PPP project without considering the uncertainty of future cash flows (Ashuri, Kashani, Molenaar, Lee, \& Lu, 2011). Real options theory was first put forward by Myers (1977) and brought a new way of thinking to investment decision theory in order to resolve the limitations of the NPV method, especially for physical assets. The analysis of real options allows investors to choose the best opportunity to invest in, giving investment decisions a broader time range and providing a longer term strategic view. PPP projects require a large scale of investment and the private sector needs to consider many uncertain factors. In the past decade, real options theory has been used to conduct research on the investment decision-making of PPP projects. Most of this research has focused on evaluation of the value of guarantee options (Almassi, McCabe, \& Thompson, 2013; Mirzadeh \& Birgisson, 2015; Wibowo \& Kochendoerfer, 2011), while some other scholars have considered the real options related to project performance, such as negotiation and early termination (Huang \& Pi, 2013; Liu \& Cheah, 2009; Xiong \& Zhang, 2016).

Table 1. Simulation techniques assisting NPV method on concession period determination

\begin{tabular}{|c|c|c|c|}
\hline Research approach & Applied project & $\begin{array}{l}\text { Research } \\
\text { result }\end{array}$ & Literature \\
\hline NPV & General projects & Time interval & Shen, $\mathrm{Li}$, and $\mathrm{Li}$ (2002) \\
\hline \multirow{2}{*}{$\begin{array}{l}\text { NPV+ Monte Carlo } \\
\text { simulation }\end{array}$} & \multirow{2}{*}{$\begin{array}{l}\text { Transportation projects, } \\
\text { port projects }\end{array}$} & Time interval & Shen and Wu (2005), Zhang (2009) \\
\hline & & Specific time & $\begin{array}{l}\text { Ng, Xie, Cheung, and Jefferies (2007), } \\
\text { Carbonara et al. (2014) }\end{array}$ \\
\hline \multirow[t]{2}{*}{$\begin{array}{l}\text { NPV + bargaining game } \\
\text { theory }\end{array}$} & \multirow[t]{2}{*}{ General projects } & Time interval & $\begin{array}{l}\text { Shen, Bao, Wu, and Lu (2007), Hanaoka } \\
\text { and Palapus (2012) }\end{array}$ \\
\hline & & Specific time & Bao, Peng, Ablanedo-Rosas, and Gao (2015) \\
\hline \multirow[t]{2}{*}{ NPV + system dynamics } & Transportation projects & Time interval & Khanzadi, Nasirzadeh, and Alipour (2012) \\
\hline & Waste-to-energy incineration projects & Specific time & Song, Song, and Zhang (2015) \\
\hline $\begin{array}{l}\text { NPV + discrete stochastic } \\
\text { process }\end{array}$ & Transportation projects & Specific time & $\mathrm{Xu}$ and Moon (2014) \\
\hline
\end{tabular}


Few studies have applied real options in order to optimise concession periods directly. Applying real options theory to concession period determination for PPP projects is conducive to making more scientific investment decisions. With the help of Monte Carlo simulation, the guarantee option has been applied to determine the concession period for toll-road and water-supply projects (Huang \& Lv, 2016; Zhao \& He, 2010). In addition to the guarantee option, project evaluation should incorporate the option to defer in order to achieve a comprehensive view, because of the uncertainty and irreversibility of such investment (Doan \& Menyah, 2012). If the government prefers to invest immediately and grant the PPP without the option to defer, the investment will only be optimal when the NPV is positive. If the NPV is negative, some incentive must compensate the private sector by an amount equivalent to the negative NPV (Rocha Armada, Pereira, \& Rodrigues, 2012).

The classical irreversible investment model developed by Dixit and Pindyck (1994) regards investment opportunities as American options and considers the value of delaying investment. Referring to this model, Lv, Ye, Liu, Shen, and Wang (2014) built a related model to optimise the concession period for tollway projects, and this model was also applied to urban rail projects (Lv, Liu, Zou, \& Gan, 2016). The D-P model can be applied only if a project has a continuous cash flow and a unique source of uncertainty, and investors can choose the time to invest. The cash flow of rental retirement villages, which mainly comes from the weekly rent, is continuous. The demand for these villages is the only uncertainty, according to which both the government and private sectors must make investment decisions. Therefore, this paper applies the option to defer in order to determine an effective concession period interval for PPP retirement village projects based on the D-P model and chooses a specific concession period to achieve maximum benefit from the whole project.

\section{Modelling concession period with option to defer for PPP retirement villages}

\subsection{Concession period interval and investment threshold for PPP retirement villages}

Investors can choose the best time for their company to implement an investment program and this choice brings an option to defer. The option to defer helps investors recognise more uncertainties before the expiration date. The determination process of the concession period for PPP retirement villages proposed in this paper consists of two steps. The first is using the D-P model with the option to defer in order to find the critical investment threshold and the concession period interval, and the second step is incorporating the value of the options into the optimisation of the concession period. There are two basic assumptions regarding the proposed PPP concession period determination model. First, the cost of investment during the construction and operation periods of the PPP retirement village project is partly or completely irreversible and the total investment is put into construction completely at the initial stage of the project without considering bank loans or other financing sources. Second, the demand for the retirement village $N$ (the number of units) is affected by several factors, such as the economic conditions, the population growth and the accommodation preferences of seniors. Therefore, demand is assumed to follow a stochastic process $\mathrm{dN}_{t}=\alpha N_{t} \mathrm{dt}+\sigma N_{t} d W$ where $t$ refers to the time, $\alpha$ is the expected growth rate, $\sigma$ is the demand volatility and $d W$ is an increment of a Wiener process (Dixit \& Pindyck, 1994).

The expected value of a PPP retirement village project for the government $F_{g}(N)$ can be expressed as:

$$
F_{g}(N)=E\left[\left(\int_{0}^{T_{c}} e^{-\rho t} X d t+\int_{T_{c}}^{T_{n}}\left(\frac{R \cdot t \cdot N_{t}}{\mu}-C_{0}\right) d t-K_{1} I_{0}\right)\right] \text {. }
$$

In Equation (1), $T_{c}$ is the concession period, $T_{n}$ is the economic life of the project, $\rho$ stands for the discount rate of the project, $\mathrm{X}$ means the annual government benefit, $R \cdot t$ represents the annual rental revenue where $\mathrm{R}$ is the weekly rent and $t$ equals 52 weeks, $\mu$ represents the proportion of rental revenue in total operation revenue, $C_{0}$ refers to the annual operation cost of the project and $K_{1}$ refers to the proportion of government investment in the total investment $I_{0}$. The project value includes the onetime government investment in the initial stage, the cash flows during the concession period and the cash flows after the transfer until the end of the project's economic life.

Due to the irreversibility of investment, the D-P model is adapted to solve the value of the option to defer and the project value. In consideration of specific conditions, the project value of the government is given by (see Appendix A):

$F_{g}(N)=\left\{\begin{array}{ll}\frac{X}{\rho}\left(1-e^{-\delta T}\right)+\frac{N}{\delta} \frac{R t e^{-\delta T}}{\mu}-\frac{C_{o}}{\rho} e^{-\delta T}-K_{1} I_{0} & N \geq N_{g} \\ \left(\frac{N}{N_{g}}\right)^{\beta_{1}}\left[\frac{X}{\rho}\left(1-e^{-\delta T}\right)+\frac{N_{g}}{\delta} \frac{R t e^{-\delta T}}{\mu}-\frac{C_{o}}{\rho} e^{-\delta T}-K_{1} I_{0}\right] N<N_{g}\end{array}\right.$,

where: $\beta_{1}=\frac{1}{2}-\frac{\rho-\delta}{\sigma^{2}}+\sqrt{\left(\frac{\rho-\delta}{\sigma^{2}}-\frac{1}{2}\right)^{2}+\frac{2 \rho}{\sigma^{2}}}>1$ and

$\delta=\rho-\alpha$, while $\alpha$ is the annual growth rate of the demand.

The investment threshold of the government can be solved as (see Appendix B):

$$
N_{g}=\delta \frac{\beta_{1}}{\beta_{1}-1} \frac{\left[K_{1} I_{0}+\frac{C_{o}}{\rho} e^{-\delta T}-\frac{X}{\rho}\left(1-e^{-\delta T}\right)\right]}{\frac{R t e^{-\delta T}}{\mu}} .
$$

The government is willing to invest in the project only when the estimated demand $N \geq N_{g}$ and has a maximum acceptable concession period $T_{g}$, which must satisfy:

$$
T_{g}=\frac{1}{\delta} \ln \left(\frac{\frac{R t N}{\mu} \frac{\beta_{1}-1}{\delta \beta_{1}}-\frac{X}{\rho}-\frac{C_{o}}{\rho}}{K_{1} I_{0}-\frac{X}{\rho}}\right)
$$


Similarly, on the other side the expected value of the private sector $F_{p}(N)$ can be written as:

$$
F_{p}(N)=E\left[\left(\int_{0}^{T_{c}} e^{-\rho t}\left(\frac{R \cdot t \cdot N_{t}}{\mu}-C_{o}-X\right) d t-K_{2} I_{0}\right)\right],
$$

where: $K_{2}$ is the proportion of private sector investment in the total investment and $K_{2}=1-K_{1}$. This value includes the one-time private investment and the cash flows during the concession period.

The solution of Equation (5) is represented as (see Appendix A):

$F_{p}(N)=\left\{\begin{array}{ll}\left(\frac{R t N}{\mu \delta}-\frac{C_{o}}{\rho}-\frac{X}{\rho}\right)\left(1-e^{-\delta T}\right)-K_{2} I_{0} & N \geq N_{p} \\ \left(\frac{N}{N_{p}}\right)^{\beta_{1}}\left[\left(\frac{R t N}{\mu \delta}-\frac{C_{o}}{\rho}-\frac{X}{\rho}\right)\left(1-e^{-\delta T}\right)-K_{2} I_{0}\right] N<N_{p},\end{array}\right.$,

The investment threshold of the private sector $N_{P}$ can be solved as (see Appendix C):

$$
N_{P}=\delta \frac{\beta_{1}}{\beta_{1}-1} \frac{1}{\frac{R t}{\mu}\left(1-e^{-\delta T}\right)}\left[K_{2} I_{0}+\left(\frac{C_{o}}{\rho}+\frac{X}{\rho}\right)\left(1-e^{-\delta T}\right)\right] \text {. }
$$

The private sector is willing to invest in the project only when the estimated demand $N \geq N_{p}$ and has a minimum acceptable concession period $T_{p}$, which must satisfy:

$$
T_{p}=\frac{1}{\delta} \ln \left(\frac{\frac{C_{o}}{\rho}+\frac{X}{\rho}-\frac{R t N}{\mu} \frac{\beta_{1}-1}{\delta \beta_{1}}}{K_{2} I_{0}+\frac{C_{o}}{\rho}+\frac{X}{\rho}-\frac{52 R N}{\mu} \frac{\beta_{1}-1}{\delta \beta_{1}}}\right) .
$$

To determine the concession period interval, the solution of $T_{g}$ and $T_{p}$ should satisfy the condition $T_{p} \leq T_{g}$ and, when $T_{p}=T_{g}$, there exists a balanced investment threshold point $N_{0}$ for both parties, which is:

$$
N_{0}=\delta \frac{\beta_{1}}{\beta_{1}-1}\left(\frac{I_{0}+\frac{C_{o}}{\rho}}{\frac{R t}{\mu}}\right) \text {. }
$$

Therefore, only when the estimated demand $\mathrm{N} \geq N_{0}$, the final concession period $T_{c}$ falls into the interval $\left[T_{p}, T_{g}\right]$ and $\mathrm{N} \geq \max \left(N_{g}, N_{p}, N_{0}\right)$ will both the government and the private sector invest in the project.

\subsection{Optimal concession period for PPP retirement villages}

The concept of extended net present value (ENPV) is now adapted to determine the optimal concession period. The ENPV of the project value is given by the sum of the original NPV of the project and the value of the real option (Cruz \& Marques, 2013; Rocha Armada, Pereira, \& Rodrigues, 2012):

$$
\operatorname{ENPV}(\mathrm{N})=\mathrm{NPV}(\mathrm{N})+\mathrm{W}(\mathrm{N})
$$

As there is a condition of incomplete information, the government expects the private sector to be willing to in- vest in the project with a positive attitude of cooperation; hence the determination of the concession period can satisfy the need for maximum overall benefit of the project. The ENPV of the project equals the sum of the government's and the private sector's ENPV, which is $\mathrm{ENPV}_{r v}=$ $\mathrm{ENPV}_{g}+\mathrm{ENPV}_{p}$ (see Appendix A):

$\mathrm{ENPV}_{r v}=\frac{R t N}{\mu \delta}-\frac{C_{0}}{\rho}-I_{0}+$

$\left(\frac{N}{N_{g}}\right)^{\beta_{1}}\left[\frac{X}{\rho}\left(1-e^{-\delta T}\right)+\frac{N_{g}}{\delta} \frac{R t e^{-\delta T}}{\mu}-\frac{C_{o}}{\rho} e^{-\delta T}-K_{1} I_{0}\right]+$

$\left(\frac{N}{N_{p}}\right)^{\beta_{1}}\left[\left(\frac{R t N}{\mu \delta}-\frac{C_{o}}{\rho}-\frac{X}{\rho}\right)\left(1-e^{-\delta T}\right)-K_{2} I_{0}\right]$.

The function of $\mathrm{ENPV}_{r v}$ is an increasing function and has a maximum value, so the equilibrium solution of the concession period $T_{c}$ can be accomplished by deriving $\mathrm{ENPV}_{r v}$ and making $\mathrm{dENPV} / d T=0$ :

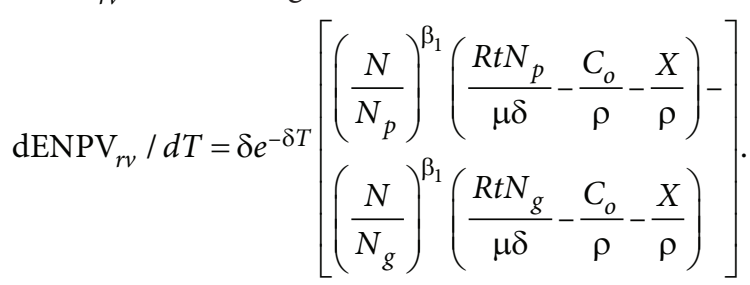

When Equation (12) $=0, \mathrm{~N}_{p}=\mathrm{N}_{g}$, so $T_{c}$ is solved as:

$$
T_{C}=\frac{1}{\delta} \ln \left(\frac{I_{0}-\frac{X}{\rho}}{K_{1} I_{0}-\frac{X}{\rho}}\right) \text {. }
$$

If $T_{C}$ satisfies the condition $T_{p} \leq T_{c} \leq T_{g}, T_{C}$ is defined as the final concession period in the contract. The equilibrium solution of the concession period $T_{C}$ is related to the amount of total investment, the proportion of government investment, the government benefit from the private sector and the discount rate.

\section{Application example}

\subsection{Concession period for a retirement village}

To verify the effectiveness of the proposed concession period model with the option to defer and to illustrate the calculation process, a new rental retirement village is considered as if being built as a PPP project. The necessary data has been collected based on current retirement villages and reasonable assumptions. The government may choose an average or a large capacity for a retirement village, as different scales may affect the length of the concession period. Therefore, two cases are chosen for the proposed retirement village: an average capacity of 50 units and a large capacity of 96 units. The floor area of each unit is $56 \mathrm{~m}^{2}$ with one bedroom. Facilities include a carpark, a small library, a dining room and a community social centre. The concession period for the new village 
will now be determined by applying the proposed model.

The total investment $I_{0}$ includes the construction costs of all the units and the facilities, a 15\% professional fee, $10 \%$ GST based on the construction costs and a 15\% contingency fee. The construction costs are estimated from the Construction Handbook. Referring to other PPP projects, it is assumed that the government provides $30 \%$ of the total investment. The operation cost, which includes the maintenance cost, can be estimated from the financial reports of a number of rental villages. A retirement village industry report indicates that the volatility level of the industry is moderate, ranging from $3 \%$ to $10 \%$. As the increasing demand for retirement villages is mainly caused by increase in the ageing population and extension of human lifespans, and remains very stable, a low volatility rate of $3 \%$ is applied in this research. The initial occupancy rate is $70 \%$ and the annual growth rate is estimated at $1.5 \%$. The rent is set at $\mathrm{AU} \$ 330$ per week, which is lower than the market price in considering the improvement to public welfare. The proportion of the rent revenue is estimated to be $60 \%$, which means $\mu=0.6$. The discount rate $\rho$ is calculated by the Capital Asset Pricing Model: $\rho=r+\beta\left(r_{m}-r\right)$, where $r=0.0267$ and represents the risk-free rate, which is the average rate of government 10-year bonds from December 2016 to November 2017, $\beta=0.5$ and is a coefficient to estimate the market risk, $r_{m}$ is the risk rate and $\left(r_{m}-r\right)$ is the equity premium, which is estimated at 5.25. So the discount rate $\rho=0.053$. The annual government benefit $X=P \cdot r$, where P represents the land price estimated from the sale price of the land from the proposed location. The calculation and analysis process have been implemented through MATLAB programming.

The values of the variables used in the modelling process are given in Table 2. Applying the data to Equation (9), the balanced investment threshold point of the average village with 50 units can be calculated as: $N_{0}=33$. Obviously $N_{0}<N=35$, hence it satisfies the condition $T_{p} \leq T_{c} \leq T_{g}$. When applying $N=35$ to Equations (4) and (8), the maximum period accepted by the government $T_{g}$ and the minimum period accepted by the private sector $T_{p}$ are solved separately. The results are $T_{g}=40$ and $T_{p}=28$. Calculating Equation (13) with the data above, the equilibrium solution for the concession period $T_{c}$ is 35.7 years. When $T_{c}=35.7$, in applying this to Equations (3) and (7) the following results can be calculated as the investment threshold points for the government $N_{g}$ and the private sector $N_{p}: N_{g}=N_{p}=33$. This satisfies the requirement $\mathrm{N} \geq \max \left(N_{g}, N_{p}, N_{0}\right)$. From these results, it can be concluded that, to achieve the maximum benefit from the whole project, the optimal concession period for the proposed PPP retirement village project should be 35.7 years. Similarly, the balanced investment threshold point of the large village with 96 units is 60 . The interval for this concession period is wider, up to $[23,43]$, and the final concession period is 35.6 years, which is almost the same as for the village with 50 units.
Table 2. Input variables of the proposed PPP retirement village

\begin{tabular}{|l|c|c|}
\hline \multicolumn{1}{|c|}{ Variables } & 50 units & 96 units \\
\hline Total investment $I_{0}$ (AUD) & $8,180,800$ & $15,358,740$ \\
\hline Annual operation cost $C_{0}$ (AUD) & 481,500 & 828,600 \\
\hline Government annual benefit $X$ (AUD) & 24,800 & 45,770 \\
\hline Initial demand $N$ (units) & 35 & 67 \\
\hline $\begin{array}{l}\text { Proportion of government } \\
\text { investment } K_{1}\end{array}$ & 0.3 & 0.3 \\
\hline $\begin{array}{l}\text { Proportion of private sector } \\
\text { investment } K_{2}\end{array}$ & 0.7 & 0.7 \\
\hline Weekly rent $R$ (AUD) & 330 & 330 \\
\hline $\begin{array}{l}\text { Proportion of rental revenue in total } \\
\text { revenue } \mu\end{array}$ & 0.6 & 0.6 \\
\hline Revenue volatility rate $\sigma(\%)$ & 3.0 & 3.0 \\
\hline Annual growth rate $\alpha(\%)$ & 1.5 & 1.5 \\
\hline Discount rate $\rho(\%)$ & 5.3 & 5.3 \\
\hline
\end{tabular}

\subsection{Implications of optimal concession period for government}

According to Equation (13), when the total investment is fixed the concession period is affected by the proportion of government investment and the discount rate. These factors relate to government capability and the economic conditions, and their impacts on the concession period should be further analysed.

When determining the concession period, the government will select its proportion of the investment based on the public budget. The private sector tends to be reluctant to invest in a PPP project if the government investment ratio is too low, as investors then bear most of the risk. But the government may reject a PPP proposal if the ratio is too high, which would mean that the project was still government-led (Xu, Peng, Qian, \& Chan, 2015). The impacts of various government investment ratios on the concession period are presented in Figure 2. When the ratio increases by $10 \%, T_{c}$ has a significant decrease, especially before the ratio reaches 0.3 , which indicates that early government investment plays a very important role in the determination of the concession period. The results also show that, with ratio increases, the concession period interval range becomes gradually narrower and the trend for $T_{c}$ is similar to that of the government boundary $T_{g}$, which indicates that the benefit growth of the private sector is less than that of the government. This is in line with the purpose of the government, which is building PPP retirement villages to improve public welfare. The trends of the two cases are quite similar but, for the minimum period of the private sector $T_{p}$, a large-scale leads to a smoother change, which implies that the private sector bears lower project risks than with an average scale.

In this research, referring to other PPP projects, the upper limit of the equilibrium solution is set at 50 years. However, most existing retirement villages have no more than 30 years' service life. Those retirement villages will enter a redevelopment stage. For the proposed 
PPP retirement village project, the government would need to invest at least $35-40 \%$ of the total investment to make $T_{c}$ lower than 30 years. A high government investment ratio would require a large proportion of the public budget and bring financial stress to the government, which might lead to rejection of the project. Therefore, in order to reduce the concession period and improve the viability of the project, there may be an opportunity to introduce third party investment into the project to adjust the capital structure, such as superannuation or age pension funds. Compared to other assets, the returns from PPP retirement villages are long term and stable (Vecchi, Hellowell, della Croce, \& Gatti, 2017), which will attract third party investment.

The only uncertainty in the project comes from the change in demand and can be reflected by the revenue volatility rate. Figure 3 shows the impacts of the volatility rate $\sigma$ on the concession period and the investment threshold $N_{0}$. It is apparent that the length of the optimal concession period $T_{c}$ is unaffected by change in $\sigma$, which is consistent with the expression in Equation (13). However, the rate of $\sigma$ could affect the interval boundaries $T_{p}$ and $T_{g}$ and thereby impact on $T_{c}$ indirectly. With $\sigma$ increases, the government boundary $T_{g}$ declines and the private sector boundary $T_{p}$ rises. This can be explained by the fact that the private sector is more sensitive to the volatility rate because a higher investment risk is associated with greater uncertainty, so that the investment threshold $N_{0}$ rises with $\sigma$ increases. The private sector prefers to delay investment due to the value of the option to defer. The upper requirement of the volatility rate in the 50 units case is about 0.6 , while the limitation increases to 0.083 in the 96 units case. The difference between these two cases indicates that, with greater uncertainty in demand a large scale is preferred, which is in line with the simulation results of $\mathrm{Li}$ and Cai (2017). When $\sigma$ continues to increase, the condition $T_{p} \leq T_{g}$ cannot be satisfied as $N_{0}>N$, which means neither party will invest in the project.

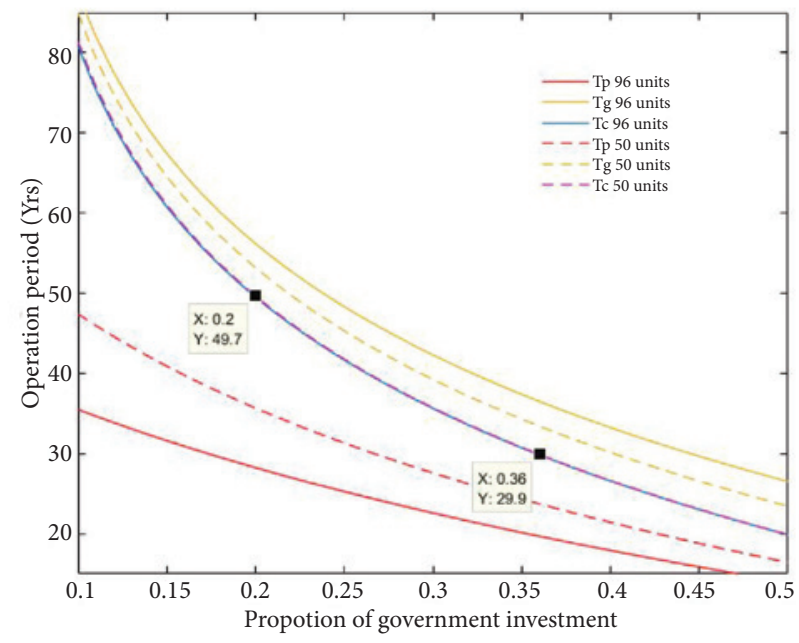

Figure 2. Impacts of the proportion of government investment on the concession period with different scales
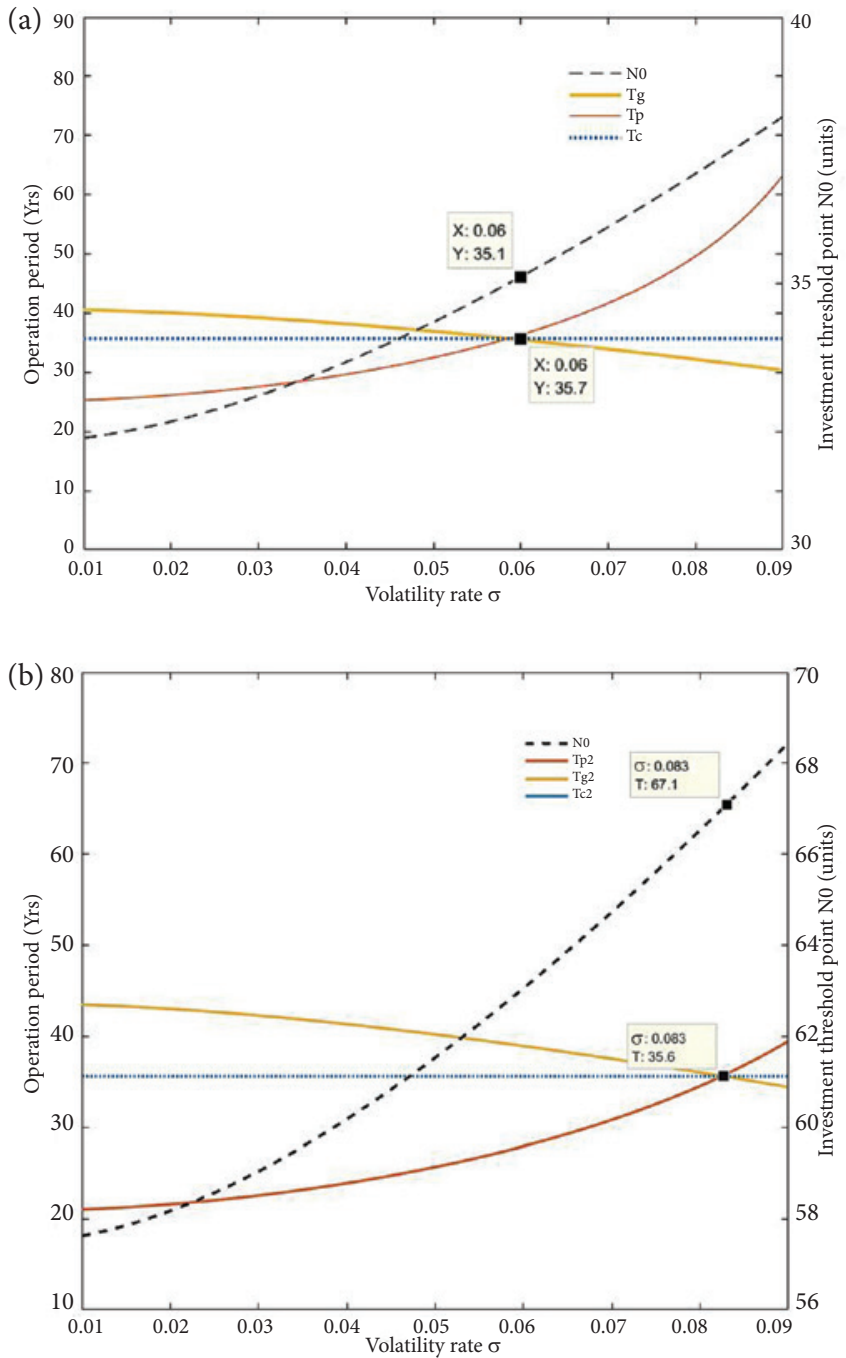

Figure 3. Impacts of the volatility rate on the concession period and investment threshold with alternative scales: (a) village with 50 units; (b) village with 96 units

Changes in economic conditions will also influence investors' decision-making and these changes can be reflected by changes in the discount rate, as the discount rate will affect the value of the project directly. Figure 4 gives the impacts of the discount rate on the concession period. It can be observed from the figure that, when the discount rate reaches $6 \%$ the three curves intersect at a point in the 50 units case, while the intersection point increases to $6.8 \%$ in the 96 units case. The results are similar to those of Figure 3 in that, compared to the average scale, the large scale works better with lower sensitivity. As $\rho$ continues to increase, $T_{c}$ has no practical meaning. Only $T_{p}$ increases slowly with a rise in the discount rate, while $T_{g}$ and $T_{c}$ continue decreasing and decline greatly before $\rho$ reaches the limitation point. This is because a higher discount rate indicates that the private sector is less likely to receive high returns and it needs a longer period to receive the expected returns.

However, a higher discount rate will cause the government to narrow the boundary in order to control excess 
(a)

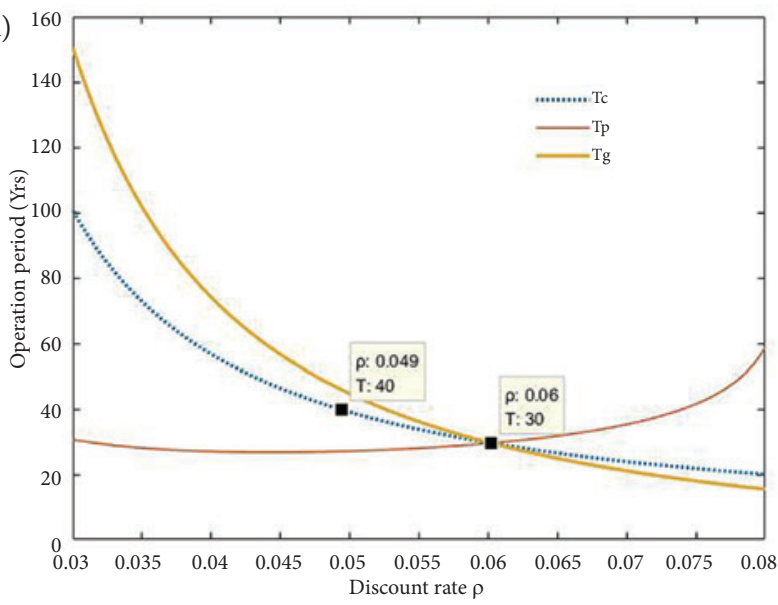

(b)

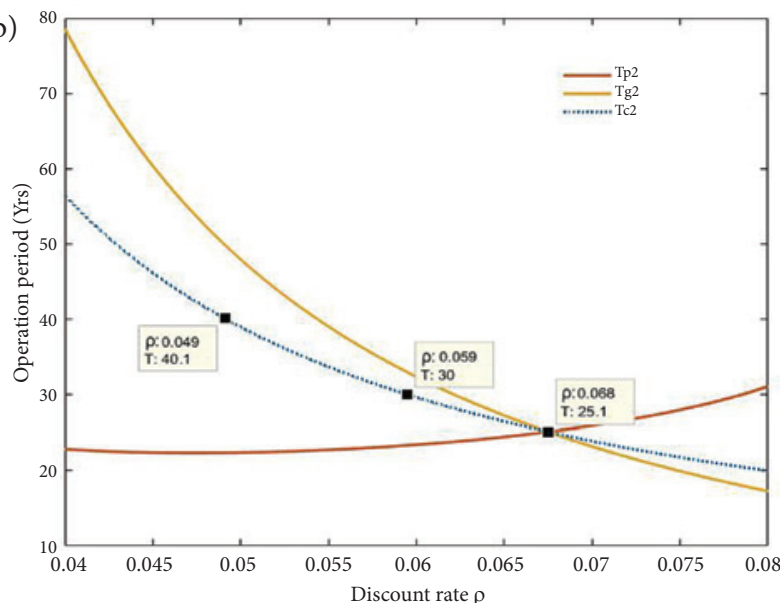

Figure 4. Impacts of the discount rate on the concession period with alternative scales: (a) village with 50 units; (b) village with 96 units

benefit. For the large scale with 96 units, the government and private sector could both delay investment until the discount rate rises to a point between $6 \%$ and $8.3 \%$ in order to reduce the concession period to within the 30 year service life of the village. But for the 50 units case, a 30 -year concession period cannot be achieved unless the government takes measures to adjust other variables to fit the process.

\subsection{Discussion}

Similar to other PPP projects, the government department overseeing any PPP retirement village will prefer the highest acceptable concession period, while the private investor will prefer the lowest limit. Both the government and private sectors can adapt the proposed model to meet each other's requirement when determining the final concession period of PPP retirement villages. Especially for the private investors, various factors such as the government investment ratio, project discount rate and operation cost will significantly affect their investment decision-making under a bidding mode with fixed price. Only when the government requirements and the invest- ment opportunities are suitable for the private investors will their attitude towards participating in a cooperative process be positive.

When economic conditions change, the government may make changes to encourage the initiation and implementation of PPP retirement village projects. Because the revenue volatility rate reflects the fluctuations in the occupancy rate of these villages, the government should focus on improving service quality and consumer satisfaction in order to stabilise the occupancy rate when the volatility rate is high. For example, the government could make explicit the range of options available to retirement village operators to improve service quality, rather than simply allowing a range of types of community care provision in retirement villages. Service quality could also be improved through providing more funds to support barrier-free design of the units and facilities, and community care for older people. To improve consumer satisfaction, the government could increase the amount of rent assistance paid to seniors and the basic Age Pension rate, or reduce the thresholds of income and asset tests. The government can also apply political strategies to allow private investors to obtain additional revenue from participation in PPP retirement villages. For example, the government could increase the size of a retirement village by providing extra land, or make the project exempt from GST. The government can also choose to allow the private sector to obtain more revenue from other services such as home care and surrounding advertisements.

To the best of the authors' knowledge, no PPP retirement villages have been constructed around the world and there is no real project data available for validation of the proposed model at this stage. For better implementation of the model in the practical setting of a retirement village, the proposed conditions of the variables used in the model and their values as used in the case study should be verified by interviewing experts in future PPP projects.

\section{Conclusions}

The demand for affordable age-friendly housing is expected to increase significantly in line with the ageing population over the coming decades. Retirement villages, with their small sizes and independent living style, are becoming more attractive to senior retirees. To make retirement villages more affordable, an opportunity exists to integrate PPP into their construction. When applying PPP to retirement villages, the concession period is one of the most important decision variables that influence the success of the project and it should be determined by considering the uncertainties. The investment decisions of the government and the private sector can be interpreted as an option to defer when associated with the optimisation of the concession period.

The contributions of this research can be summarised in relation to two aspects. First, this research proposes 
PPP as a new procurement method for the construction of retirement villages to improve the independent living environment for older people. Second, this research integrates early government investment into a real options model with the option to defer in order to determine the concession period. The results of the empirical study verify the calculation process and show that the proposed model is a valid tool to support governments in decisionmaking around the concession period, especially when a project is otherwise financially non-viable. The analysis of the main variables which affect the concession period has indicated that an increase in investment scale is beneficial in improving the economic viability of PPP retirement village projects. The optimal concession period decreases with increases in the government investment ratio and the discount rate. The analysis has also provided some implications for governments in relation to taking their financial capability and the economic conditions into consideration. The recommendations include introducing third party investment, increasing the CRA amount and Age Pension rate, making these projects exempt from GST and offering rate rebates. This research provides a new perspective for the government and the retirement village industry to consider in applying PPP to retirement villages, and offers benefits to the development of the industry for ageing services.

\section{Acknowledgements}

The authors would like to thank the anonymous referees for their insightful comments and valuable suggestions on an earlier version of the paper. The first author is grateful to the China Scholarship Council (CSC) for a PhD scholarship (No. 201508370071).

\section{References}

Aged and Community Service Australia. (2015). The future of housing for older Australians. Retrieved from https://bit. ly/2yzpa3a

Alam, Q., Kabir, M. H., \& Chaudhri, V. (2014). Managing infrastructure projects in Australia: a shift from a contractual to a collaborative public management strategy. Administration \& Society, 46(4), 422-449.

https://doi.org/10.1177/0095399712459728

Almassi, A., McCabe, B., \& Thompson, M. (2013). Real optionsbased approach for valuation of government guarantees in public-private partnerships. Journal of Infrastructure Systems, 19(2), 196-204.

https://doi.org/10.1061/(ASCE)IS.1943-555X.0000117

Ashuri, B., Kashani, H., Molenaar, K., Lee, S., \& Lu, J. (2011). Risk-neutral pricing approach for evaluating BOT highway projects with government minimum revenue guarantee options. Journal of Construction Engineering and Management, 138(4), 545-557.

https://doi.org/10.1061/(ASCE)CO.1943-7862.0000447

Bao, H., Peng, Y., Ablanedo-Rosas, J. H., \& Gao, H. (2015). An alternative incomplete information bargaining model for identifying the reasonable concession period of a BOT project. International Journal of Project Management, 33(5), 1151-1159. https://doi.org/10.1016/j.ijproman.2014.12.004

Brasor, P., \& Tsubuku, M. (2014, 6 January). Retirement homes come of age in booming market. Retrieved from https://bit. ly/2xmP75s

Carbonara, N., Costantino, N., \& Pellegrino, R. (2014). Concession period for PPPs: a win-win model for a fair risk sharing. International Journal of Project Management, 32(7), 12231232. https://doi.org/10.1016/j.ijproman.2014.01.007

COTA Australia. (2017, 22 June). AAA Housing for older Australians - making it affordable, accessible and appropriatesummary remarks. 2017 National Policy Forum. Retrieved from http://bit.ly/2IBQT40

Cruz, C. O., \& Marques, R. C. (2013). Flexible contracts to cope with uncertainty in public-private partnerships. International Journal of Project Management, 31(3), 473-483. https://doi.org/10.1016/j.ijproman.2012.09.006

Dixit, A. K., \& Pindyck, R. S. (1994). Investment under uncertainty. Princeton, New Jersey: Princeton University Press.

Doan, P., \& Menyah, K. (2012). Impact of irreversibility and uncertainty on the timing of infrastructure projects. Journal of Construction Engineering and Management, 139(3), 331-338. https://doi.org/10.1061/(ASCE)CO.1943-7862.0000615

Gardner, I. L., Browning, C., \& Kendig, H. (2005). Accommodation options in later life: retirement village or community living? Australasian Journal on Ageing, 24(4), 188-195. https://doi.org/10.1111/j.1741-6612.2005.00121.x

Hanaoka, S., \& Palapus, H. P. (2012). Reasonable concession period for build-operate-transfer road projects in the Philippines. International Journal of Project Management, 30(8), 938-949. https://doi.org/10.1016/jiijproman.2012.02.001

Huang, D. W., \& Lv, Z. Y. (2016). Concession period of PPP projects based on security option. Journal of Economics of Water Resources, 34(6), 26-29.

Huang, Y.-L., \& Pi, C.-C. (2013). Real-option valuation of buildoperate-transfer infrastructure projects under performance bonding. Journal of Construction Engineering and Management, 140(5), 04013068. https://doi.org/10.1061/(ASCE)CO.1943-7862.0000821

IBISWorld. (2017). Coming of age: revenue soars as retiring baby boomers drive industry demand (Industry Report OD5534 Retirement Villages in Australia). Retrieved from www.ibisworld.com.au

Jones, A., Howe, A., Tilse, C., Bartlett, H., \& Stimson, B. (2010). Service integrated housing for Australians in later life (AHURI Final Report No. 141). Retrieved from https://bit.ly/2K0NAb5

Khanzadi, M., Nasirzadeh, F., \& Alipour, M. (2012). Integrating system dynamics and fuzzy logic modeling to determine concession period in BOT projects. Automation in Construction, 22, 368-376. https://doi.org/10.1016/j.autcon.2011.09.015

Li, S., \& Cai, H. (2017). Government incentive impacts on private investment behaviors under demand uncertainty. Transportation Research Part E: Logistics and Transportation Review, 101, 115-129. https://doi.org/10.1016/j.tre.2017.03.007

Liu, J., \& Cheah, C. Y. (2009). Real option application in PPP/PFI project negotiation. Construction Management and Economics, 27(4), 331-342. https://doi.org/10.1080/01446190902807071

Liu, S., Ma, L., \& Liu, C. (2016). Understanding senior community residents for better construction of retirement villages. Proceedings of the Australasian Universities Building Education Association Annual Conference 2016: Radical Innovation in the Built Environment (pp. 525-534). Carins, Queensland, Australia. 
Lv, J., Liu, W., Zou, Q., \& Gan, L. (2016). Cooperative game model on concession period in SBOT project under uncertainty. Journal of Industrial Engineering/Engineering Management, 30(3), 209-215.

Lv, J., Ye, G., Liu, W., Shen, L., \& Wang, H. (2014). Alternative model for determining the optimal concession period in managing BOT transportation projects. Journal of Management in Engineering, 31(4), 04014066.

https://doi.org/10.1061/(ASCE)ME.1943-5479.0000291

Mirzadeh, I., \& Birgisson, B. (2015). Evaluation of highway projects under government support mechanisms based on an option-pricing framework. Journal of Construction Engineering and Management, 142(4), 04015094. https://doi.org/10.1061/(ASCE)CO.1943-7862.0001079

Myers, S. C. (1977). Determinants of corporate borrowing. Journal of Financial Economics, 5(2), 147-175.

National Commission of Audit. (2014). Towards Responsible Government: The Report of the National Commission of Audit Phase One. Retrieved from https://bit.ly/2M8Q03O

Ng, S. T., Xie, J., Cheung, Y. K., \& Jefferies, M. (2007). A simulation model for optimizing the concession period of publicprivate partnerships schemes. International Journal of Project Management, 25(8), 791-798.

https://doi.org/10.1016/j.ijproman.2007.05.004

Osei-Kyei, R., Chan, A. P., Javed, A. A., \& Ameyaw, E. E. (2017). Critical success criteria for public-private partnership projects: international experts' opinion. International Journal of Strategic Property Management, 21(1), 87-100.

https://doi.org/10.3846/1648715X.2016.1246388

Owen, S. (2015, 11 November). The future of retirement living. Retrieved from http://bit.ly/2zOj3Iq

Retirement Village Association. (2011). Caring for Older Australians: Response to the Productivity Commission Draft Report (Submission DR900). Retrieved from https://bit.ly/2hZPhVN

Rocha Armada, M. J., Pereira, P. J., \& Rodrigues, A. (2012). Optimal subsidies and guarantees in public-private partnerships. The European Journal of Finance, 18(5), 469-495. https://doi.org/10.1080/1351847X.2011.639789

Shen, L., Bao, H., Wu, Y., \& Lu, W. (2007). Using bargaininggame theory for negotiating concession period for BOT-type contract. Journal of Construction Engineering and Management, 133(5), 385-392. https://doi.org/10.1061/(ASCE)07339364(2007)133:5(385)

Shen, L., Li, H., \& Li, Q. (2002). Alternative concession model for build operate transfer contract projects. Journal of Construction Engineering and Management, 128(4), 326-330. https://doi.org/10.1061/(ASCE)0733-9364(2002)128:4(326)

Shen, L., \& Wu, Y. (2005). Risk concession model for build/operate/transfer contract projects. Journal of Construction Engineering and Management, 131(2), 211-220.

https://doi.org/10.1061/(ASCE)0733-9364(2005)131:2(211)

Song, J., Song, D., \& Zhang, D. (2015). Modeling the concession period and subsidy for bot waste-to-energy incineration projects. Journal of Construction Engineering and Management, 141(10), 04015033.

https://doi.org/10.1061/(ASCE)CO.1943-7862.0001005

Stimson, R. J., \& McCrea, R. (2004). A push-pull framework for modelling the relocation of retirees to a retirement village: the Australian experience. Environment and Planning A, 36(8), 1451-1470. https://doi.org/10.1068/a36206
Tang, X., \& Feng, L. (2016). Research on the financing model of senior housing based on PPP. Proceedings of the International Conference on Construction and Real Estate Management 2016 (pp. 896-902). Edmonton, Canada.

Tsutsui, T. (2010). The current state and future development of the long-term care insurance system in Japan. Journal of the National Institute of Public Health, 59, 372-379.

Vecchi, V., Hellowell, M., della Croce, R., \& Gatti, S. (2017). Government policies to enhance access to credit for infrastructure-based PPPs: an approach to classification and appraisal. Public Money \& Management, 37(2), 133-140. https://doi.org/10.1080/09540962.2016.1266173

Wibowo, A., \& Kochendoerfer, B. (2011). Selecting BOT/PPP infrastructure projects for government guarantee portfolio under conditions of budget and risk in the Indonesian context. Journal of Construction Engineering and Management, 137(7), 512522. https://doi.org/10.1061/(ASCE)CO.1943-7862.0000312

Wood, G., Ong, R., \& Cigdem, M. (2014). Housing affordability dynamics: new insights from the last decade (AHURI Final Report No. 233). Retrieved from https://bit.ly/2MOt0bx

Wood, G., Ong, R., \& Cigdem, M. (2017). Australian demographic trends and implications for housing assistance programs (AHURI Final Report No. 286). Retrieved from https://bit.ly/2K9C3ST

Xia, B., Zuo, J., Skitmore, M., Chen, Q., \& Rarasati, A. (2015). Sustainable retirement village for older people: a case study in Brisbane, Australia. International Journal of Strategic Property Management, 19(2), 149-158. https://doi.org/10.3846/1648715X.2015.1029564

Xiong, W., \& Zhang, X. (2016). The real option value of renegotiation in public-private partnerships. Journal of Construction Engineering and Management, 142(8). https://doi.org/10.1061/(ASCE)CO.1943-7862.0001130

Xu, J., \& Moon, S. (2014). Stochastic revenue and cost model for determining a BOT concession period under multiple project constraints. Journal of Management in Engineering, 30(3). https://doi.org/10.1061/(ASCE)ME.1943-5479.0000182

Xu, Y., Peng, Y., Qian, Q. K., \& Chan, A. P. (2015). An alternative model to determine the financing structure of PPP-based young graduate apartments in China: a case study of Hangzhou. Sustainability, 7(5), 5720-5734. https://doi.org/10.3390/su7055720

Yang, L., Zhou, Y., \& Tan, L. (2017). The division of roles in operation models for PPP elderly housing projects. Proceedings of the International Conference on Construction and Real Estate Management 2017 (pp. 396-403). Guangzhou, China.

Yu, C. Y., \& Lam, K. C. (2013). A decision support system for the determination of concession period length in transportation project under BOT contract. Automation in Construction, 31, 114-127. https://doi.org/10.1016/j.autcon.2012.11.012

Yuen, B., \& Soh, E. (2017). Housing for older people in Singapore: an annotated bibliography. Retrieved from https://bit. ly/2JZPkS0

Zhang, X. (2009). Win-win concession period determination methodology. Journal of Construction Engineering and Management, 135(6), 550-558. https://doi.org/10.1061/(ASCE)CO.1943-7862.0000012

Zhao, G., \& He, T. (2010). The research on the concession term decision-making model for BOT projects based on real option. Journal of Beijing Institute of Technology (Social Science Edition), 12(5), 27-30. 


\section{Appendix A}

The value of the option to invest in the project $W(N)$ must satisfy:

$$
\frac{1}{2} \sigma^{2} N^{2} W^{\prime \prime}(N)+\alpha N W^{\prime}(N)-\rho W(N)=0 .
$$

The general solution of Equation (A1) is:

$$
W(N)=A_{1} N^{\beta_{1}}+A_{2} N^{\beta_{2}},
$$

where: $\beta_{1}$ and $\beta_{2}$ are the solutions of the following quadratic equations:

$$
\begin{aligned}
& \frac{1}{2} \sigma^{2} \beta(\beta-1)+(\rho-\delta) \beta-\rho=0 ; \\
& \beta_{1}=\frac{1}{2}-\frac{\rho-\delta}{\sigma^{2}}+\sqrt{\left(\frac{\rho-\delta}{\sigma^{2}}-\frac{1}{2}\right)^{2}+\frac{2 \rho}{\sigma^{2}}}>1 ; \\
& \beta_{2}=\frac{1}{2}-\frac{\rho-\delta}{\sigma^{2}}-\sqrt{\left(\frac{\rho-\delta}{\sigma^{2}}-\frac{1}{2}\right)^{2}+\frac{2 \rho}{\sigma^{2}}}<0 .
\end{aligned}
$$

The value function $\mathrm{W}(\mathrm{N})$ for the option to invest should satisfy the following boundary conditions:

$$
\left\{\begin{array}{c}
W(0)=0 \\
W\left(N^{*}\right)=V\left(N^{*}\right)-I, \\
W^{\prime}\left(N^{*}\right)=V^{\prime}\left(N^{*}\right)
\end{array}\right.
$$

where: $V$ represents the expected presented value of the project; $I$ is the sunk cost of the project and $W(0)=0$ indicates $A_{2}=0$ when $N \geq N^{*}$ investors will invest in the project immediately and when $N<N^{*}$ investors will hold the option value $\mathrm{W}$ and wait until the threshold is first met to obtain the value of $V-I$.

Therefore, the project value $\mathrm{F}(\mathrm{N})$ can be stated as:

$$
F(N)=\left\{\begin{array}{ll}
V-I & N \geq N^{*} \\
\left(\frac{N}{N^{*}}\right)^{\beta_{1}}(V-I) & N<N^{*}
\end{array} .\right.
$$

In Equation (A7), the NPV of the project equals $V-I$ when $N \geq N^{*}$ while the value of option W equals $\left(\frac{N}{N^{*}}\right)^{\beta_{1}}(V-I)$. According to Equations (2), (6) and (10), the ENPV of the government and the private sector can be written as the following:

$$
\begin{aligned}
\mathrm{ENPV}_{g}= & \frac{X}{\rho}\left(1-e^{-\delta T}\right)+\frac{N}{\delta} \frac{R t e^{-\delta T}}{\mu}-\frac{C_{o}}{\rho} e^{-\delta T}-K_{1} I_{0}+ \\
\left(\frac{N}{N_{g}}\right)^{\beta_{1}}\left[\frac{X}{\rho}\left(1-e^{-\delta T}\right)+\frac{N_{g}}{\delta} \frac{R t e^{-\delta T}}{\mu}-\frac{C_{o}}{\rho} e^{-\delta T}-K_{1} I_{0}\right]^{;} & \\
\mathrm{ENPV}_{p}= & \left(\frac{R t N}{\mu \delta}-\frac{C_{o}}{\rho}-\frac{X}{\rho}\right)\left(1-e^{-\delta T}\right)-K_{2} I_{0}+\left(\frac{N}{N_{p}}\right)^{\beta_{1}} \\
& {\left[\left(\frac{R t N_{p}}{\mu \delta}-\frac{C_{o}}{\rho}-\frac{X}{\rho}\right)\left(1-e^{-\delta T}\right)-K_{2} I_{0}\right] }
\end{aligned}
$$

\section{Appendix B}

Referring to Dixit and Pindyck (1994), the initial condition, value-matching and smooth-pasting conditions of the government can be written as the following according to Equations (2) and (A6):

$$
\left\{\begin{array}{c}
F(0)=0 \\
A_{1}\left(N_{g}\right)^{\beta_{1}}=\frac{X}{\rho}\left(1-e^{-\delta T}\right)+\frac{N_{g}}{\delta} \frac{52 \mathrm{Re}^{-\delta T}}{\mu}-\frac{C_{o}}{\rho} e^{-\delta T}-K_{1} I_{0} \\
\beta_{1} A_{1}\left(N_{g}\right)^{\beta_{1}-1}=\frac{\left(52 \mathrm{Re}^{-\delta T} / \mu\right)}{\delta} .
\end{array}\right.
$$

\section{Appendix C}

Referring to Dixit and Pindyck (1994), the initial condition, value-matching and smooth-pasting conditions of the private sector can be written as the following according to Equations (6) and (A6):

$$
\left\{\begin{array}{c}
F(0)=0 \\
A_{1}\left(N_{p}\right)^{\beta_{1}}=\left(\frac{52 R N_{p}}{\mu \delta}-\frac{C_{o}}{\rho}-\frac{X}{\rho}\right)\left(1-e^{-\delta T}\right)-K_{2} I_{0} . \\
\beta_{1} A_{1}\left(N_{p}\right)^{\beta_{1}-1}=\frac{52 R\left(1-e^{-\delta T}\right)}{\mu \delta}
\end{array}\right.
$$

